Editorial

Special Issue in memory of Abe Sklar

Open Access

\author{
Giovanni Puccetti*
}

\title{
Special Issue on copulas in memory of Abe Sklar (1925-2020)
}

https://doi.org/10.1515/demo-2021-0109

Received June 30, 2021; accepted July 1, 2021

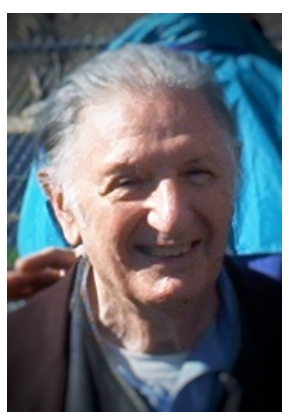

Abe (born Abraham) Sklar, one of the milestone personalities in the field of copulas and dependence modeling, passed away on October 30, 2020 at the age of 94. Soon after, I received a request from some of his friends and collaborators to publish a Special Issue devoted to his memory. I am very glad that many eminent colleagues made this Special Issue not only possible but also a gratifying reading. For the occasion, I left the handling of the review process in the safe hands of Roger Nelsen and Carlo Sempi, whom I thank for their kind cooperation.

In 2015, when Dependence Modeling started its Interview Article series, the name of Abe was the first on the list. Some members of the editorial board tried to contact him, and even managed to send by post a list of questions to be answered. Unfortunately, we never heard back. Personally, I always felt this was a missing tile in our journal, almost a shame. Finally, this gap has been bridged by Christian Genest, who wrote a magnificent tribute that will open the Special Issue.

Presumably, if you are reading these words, you have already encountered Sklar's theorem in your career. Can you remember the first occurrence? On my side, it happened as an undergraduate student in Florence. I remember that I was a bit sick one day and could not wait to leave the class and go home. One professor urged me to stay since the department was having a distinguished speaker that day: Paul Embrechts. In the early days of Risk Aggregation via Copulas, that was the first time I noticed the title Sklar's Theorem on one slide. Incidentally, Paul delivered the first interview in the series, years later.

Below is what Roger and Carlo had to say. And you, can you remember your first encounter with Abe?

Roger Nelsen: During the 1983-84 academic year I had a "sabbatical lectureship" at the University of Massachusetts in Amherst. It was during that year that I met Berthold Schweizer, who not only introduced me to copulas, but also to several visitors to Amherst that year, including Abe Sklar and Jerry Frank (and others). That year changed my life.

Carlo Sempi: I well remember my first meeting with Abe; it was on the spring of 1972 in Waterloo, where Abe usually came to visit alone or accompanied with Berthold Schweizer or Jerry Frank. He used to come there to talk with János Aczél, Bruno Forte (my PhD supervisor) and Michael McKiernan.

${ }^{\star}$ Corresponding Author: Giovanni Puccetti: Dipartimento di Economia, Management e Metodi Quantitativi, Università di Milano, Italy. E-mail: giovanni.puccetti@unimi.it

Photo courtesy of J.A. Rodríguez-Lallena. 